\title{
Structural Analysis of Carbon Nanotubes of Various Diameters Grown by Spray Pyrolysis using Raman Spectroscopy
}

\author{
E.G. Ordoñez-Casanova ${ }^{1,2}$, M. Román-Aguirre' ${ }^{2}$, A. Aguilar-Elguezabal, ${ }^{2}$, F. Espinosa-Magaña’ ${ }^{2}$ \\ ${ }^{1}$ Universidad Autónoma de Ciudad Juárez. AV. del Charro 450 N., C.P. 32310, Juárez, Chih, México. \\ ${ }^{2}$ Centro de Investigación en Materiales Avanzados, S.C., Miguel de Cervantes 120, Chihuaua, Chih., \\ México 31109
}

Carbon nanotubes of various diameters and length were grown through the alternative spray pyrolysis method [1-2], using propanol, buthanol and cyclohexanol as the carbon source, at temperatures higher than $700^{\circ} \mathrm{C}$. In this investigation,we present a comparative analysis of the structures and morphology of the three samples by Raman spectroscopy in order to verify whether it is possible, by using this method, to obtain carbon nanotubes of small diameters at a low cost. The Raman spectra were acquired by the LabRam Horiba HR system using a He- Ne laser at $632.8 \mathrm{~nm}$ and $14.2 \mathrm{~mW}$, equipped with a CCD detector column at $75^{\circ} \mathrm{C}$. The resolution obtained was of approximately $1 \mathrm{~cm}^{-1}$.

According to the literature, this study presents the responses found at different frequency regions: (1) The peaks occurring at a low frequency $<200 \mathrm{~cm}^{-1}$ are characteristic only of SWNT assigned to RBM (Radial Breathing Mode), and their frequency depends essentially on the diameter of the nanotubes [3]. (2) The peak at $1340 \mathrm{~cm}^{-1}$ is assigned to the poorly-organized residual graphite. In this region the peak is related to the so-called D band (Band Disorder) [4-5].(3) The frequencies between $1500 \mathrm{~cm}^{-1}$ and $1600 \mathrm{~cm}^{-1}$ are related to the $\mathrm{G}$ band and are highly characteristic of single nanotubes and multiple wall, These frequencies correspond to a splitting of the graphite extension mode (stretching mode) [3-5]. (4) A second order mode vibration, between $2450 \mathrm{~cm}^{-1}$ and $2650 \mathrm{~cm}^{-1}$, is assigned to the first on-tone mode and to the D mode, sometimes called $\mathrm{G}^{\prime}$ [3-5].

Figure 1(a) shows the Raman spectrum of the propanol sample at high frequencies, from 500 to $3000 \mathrm{~cm}$ -1 . The characteristic D band and G band peaks are observed. Band D is at $1321 \mathrm{~cm}^{-1}$, and it is more intense than the $\mathrm{G}$ band at $1582 \mathrm{~cm}^{-1}$ given. This indicates the presence of poorly organized graphite and the presence of possible defects in carbon nanotubes. The presence of the band $\mathrm{G}^{\prime} 2635 \mathrm{~cm}^{-1}$, corresponds to second order dispersal processes [6]. The fact that both bands, D and $\mathrm{G}^{\text {', have high }}$ intensity peaks indicates structural imperfections in the sample. Figure 1(b) shows a Raman spectrum of low frequency region. Three peaks around $161 \mathrm{~cm}^{-1}, 223 \mathrm{~cm}^{-1}$ and $267 \mathrm{~cm}^{-1}$ are featured. The first two peaks indicate the presence of single-walled nanotubes with different chirality, and the third peak nearby $267 \mathrm{~cm}^{-1}$, corresponds to the response of the quartz substrate used for the growth of nanotubes.

Figure 2(a) displays the Raman spectra of the butanol sample in the high frequency region. We can observe that Band D is at $1340 \mathrm{~cm} \mathrm{-1}$, and Band $G$ is given at $1587 \mathrm{~cm}^{-1}$ and $2663 \mathrm{~cm}^{-1}$. Bands $\mathrm{G}^{\prime}$ and $\mathrm{D}$, as propanol , are stronger than Band G, thus indicating a high density of structural imperfections, possibly poorly-organized graphite. In Figure 2(b), the low frequency region, we can observe peaks at $154 \mathrm{~cm}^{-1}$ and $229 \mathrm{~cm}^{-1}$ and $294 \mathrm{~cm}^{-1}$. By considerating only the first two peaks, the possible presence of single-walled nanotubes of various types of chirality can be confirmed. The peak around $294 \mathrm{~cm}^{-1}$ is related to the substrate.The cyclohexanol sample, where carbon nanotubes were grown at temperatures of $850{ }^{\circ} \mathrm{C}$, can be observed in Figure 3(a). Here, Band D is located at $1332 \mathrm{~cm}^{-1}$, Band G at $1597 \mathrm{~cm}^{-1}$ 
and Band $\mathrm{G}^{`}$ at $2657 \mathrm{~cm}^{-1}$. In this sample, the intensity of Band D is lower, indicating that the sample has a low density of structural imperfections as well as poorly-organized graphite.Figure 3(b). Shows low energies where two predominant curves around $147 \mathrm{~cm}^{-1}$ and $186 \mathrm{~cm}^{-1}$ are observed, indicating two possible types of single-walled nanotubes with different diameters. The other peaks present are related to the quartz substrate.

In conclusion; carbon nanotubes were grown at a temperature of $700^{\circ} \mathrm{C}$ for propanol and buthanol. In the case Cyclohexanol, they were grown at $850^{\circ} \mathrm{C}$. Raman spectroscopy reveals that the three samples containing the presence of possible carbon nanotubes of small diameters answer to regions of very low frequency. However, all samples with structural defects by analysis of their responses occurred at high energies, which challenges us to continue testing to get better quality nanotubes and small diameters at a low cost.

\section{References:}

[1] Ordoñez-Casanova, E. G., Román-Aguirre, M., Aguilar-Elguezabal, A.,Espinosa-Magaña, F. (2013). Synthesis of Carbon Nanotubes of Few Walls Using Aliphatic Alcohols. Materials, 6 (6), 2534-2542.

[2] Ordonez-Casanova, E., et al. "Characterization of Few-Walled Carbon Nanotubes Using Alcohols Aliphatic as Carbon Source." Microscopy and Microanalysis 19.S2 (2013): 1608-1609.

[3] Dresselhaus, M. S., Dresselhaus, G., Saito, R., \& Jorio, A. (2008). Raman spectroscopy of carbon nanotubes. Contemporary Concepts of Condensed Matter Science, 3, 83-108.

[4] Bachilo, S. M., Strano, M. S., Kittrell, C., Hauge, R. H., Smalley, R. E., \& Weisman, R. B. (2002). Structure-assigned optical spectra of single-walled carbon nanotubes. Science, 298(5602), 2361-2366.

[5] Bergstrom Jr, R., \& Knoesel, E. (2007). Raman Spectroscopy of Carbon Nanotubes. Bulletin of the American Physical Society, 52.

[6] Dresselhaus, M. S., Dresselhaus, G., \& Jorio, A. (2007). Raman spectroscopy of carbon nanotubes. The Journal of Physical Chemistry C, 111(48), 17887-17893
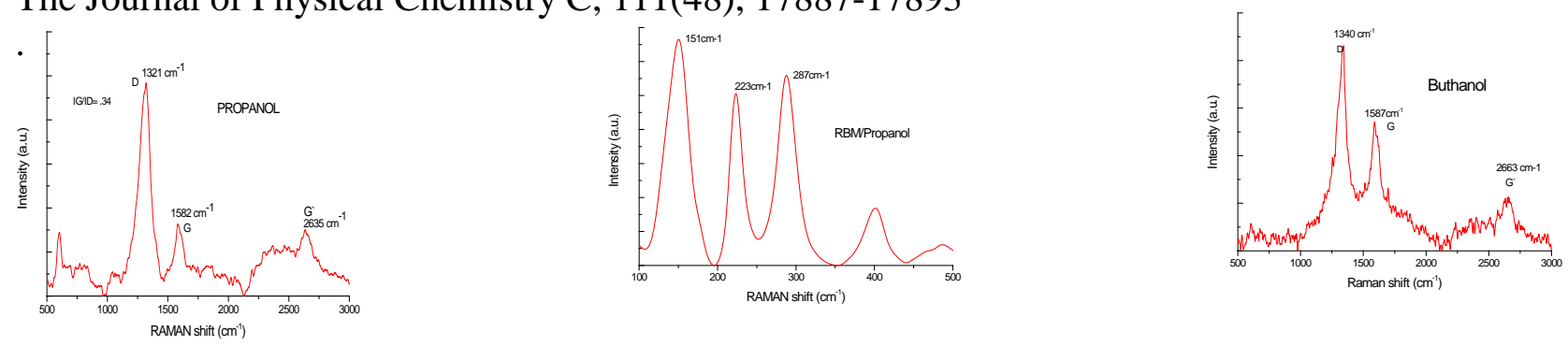

Figures 1a, Raman spectrum of the propanol sample at high energies.. 1b Raman spectrum of the propanol sample at low energies.2a, Raman spectrum of the buthanol sample at high energies.
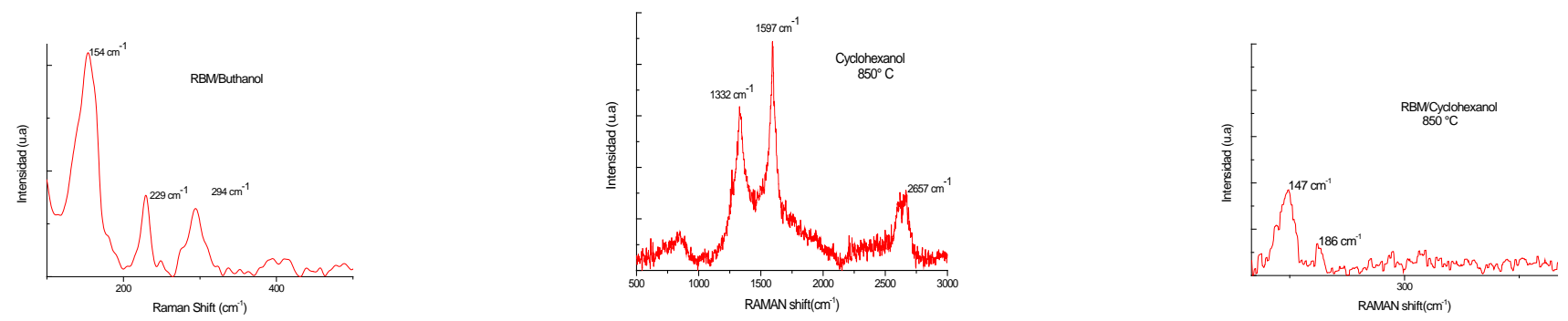

Figures 2 b Raman spectrum of the buthanol sample at low energies.3a Raman spectrum of the cyclohexanol sample at high energies.3b. Raman spectrum of the cyclohexanol sample at low energies. 